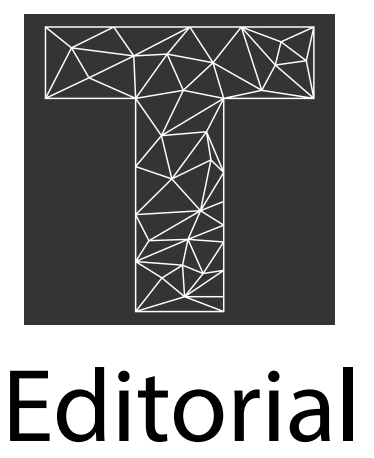

\title{
“DEMANDA DE JUSTICIA PARA MARÍA TACSAN FRENTE A LA POLÍTICA DE INEQUIDAD EN EL CONTINENTE"
}

Trama, la Revista de Ciencias Sociales y Humanidades del Instituto Tecnológico de Costa Rica publica el volumen 9, número 2, julio-diciembre de 2020, con seis manuscritos inéditos y originales. Estos trabajos reflexionan sobre distintas problemáticas sociales, culturales, económicas, ecológicas y políticas en Nuestra América Latina y el Caribe. En este contexto, esta publicación pone en perspectiva que la región está asediada por políticas estructurales de corte neoliberal; el debilitamiento de la institucionalidad pública, el estado social y el recorte a la inversión pública; la injerencia de poderes fácticos, corporativos e imperiales en el Estado de derecho; la corrupción, evasión y elusión fiscal; el ecocidio; las masacres de líderes y lideresas sociales; los feminicidios; el desempleo estructural y la explotación laboral; el incremento exponencial de la deuda externa e interna, la interdependencia estructural y los condicionamientos cruzados de organismos financieros internacionales hacia las economías de países emergentes; la crisis económica del capital y la crisis sanitaria generada por el COVID-19 a escala global; así como complejos y naturalizados mecanismos estructurales y socioculturales a través de los cuales opera el poder y la política, con de agudos impactos que exacerban la desigualdad, inequidad, injusticia, violencia e involución de los derechos humanos en el continente. De ahí que estos trabajos dejan ver estudio crítico de nuestras realidades. 


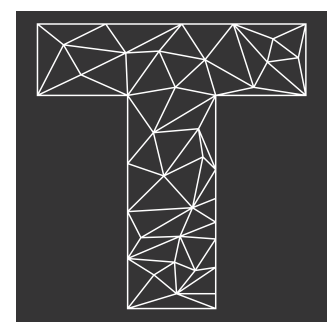

y la construcción urgente de alterativas para el bien común, la equidad y la justicia eco-sistémica.

En este sentido, el Consejo Científico - Editorial de Trama, siendo consecuentes con los objetivos de esta revista académica e internacional asume el desafío de:

1. Construir un espacio de discusión teórica, metodológica, epistemológica y de la praxis de las ciencias sociales, las humanidades, la filosofía, el derecho y disciplinas afines con las ingenierías y las ciencias naturales.

2. Comunicar conocimiento producido desde procesos de enseñanza-aprendizaje, investigación, extensión y acción social, acordes con un diálogo de saberes, de cara a los desafíos que presenta el mundo contemporáneo.

Los artículos publicados en este nuevo número contribuyen a construir ese diálogo de saberes desde los complejos y profundos vínculos de la universidad pública con nuestras sociedades.

Eduardo Fernández, profesor e investigador de la Universidad de Guanajuato reflexiona sobre la historia reciente de la migración internacional en el estado de Guanajuato, México. Para ello, presenta índices y estadísticas globales de la migración internacional asociada con la intensidad migratoria, remesas e inversión 


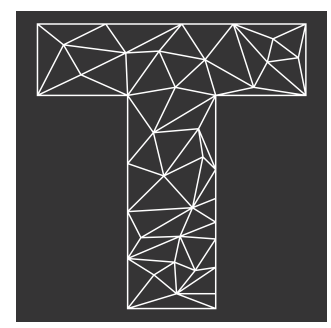

migrante en ese estado de la federación mexicana durante el siglo XXI, como un insumo para fines académicos y la gestión de políticas públicas. Desde la Teoría del Proceso Migratorio Fernández plantea inquietudes historiográficas contemporáneas y brinda una gama de elementos epistemológicos para su análisis. En este contexto, nuestro autor sostiene que la migración es concebida como un proceso histórico-social que requiere ser entendida como un fenómeno con causas e impactos socioeconómicos, políticos, sociales, culturales, psicológicos en estrecha relación con su historia; así como un fenómeno multifacético y en perspectiva histórica, multidimencional y en constante transformación. Por ello, se debe entender que cualquier movimiento migratorio puede ser investigado como producto del encadenamiento entre macroestructuras, mesoestructuras y microestructuras. Fernández concluye que Guanajuato es parte de la Región Histórica de la migración internacional en México y esta realidad permea las estructuras subjetivas, simbólicas, políticas, económicas y familiares de un amplio sector de la población de la entidad. Desde la época de la colonia, este estado mexicano ha sido un destino importante de crecimiento agropecuario, minero, y últimamente de industrias de la trasformación y servicios, y ha detonado por ende el empleo y, la migración internacional a Estados Unidos.

Álvaro Liendo Moscoso, Daniel Caravedo Ayasca y Sttefany Ruiz Lozada analizan críticamente la historia de lucha del movimiento estudiantil en la Universidad Nacional Federico Villarreal, en Lima, Perú, contra la corrupción, en el contexto de adecuación y 


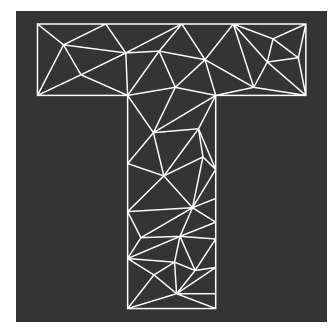

aprobación por el Congreso de la República de ese país suramericano entre 2013 y 2016 de la Ley Universitaria número 30220. Desde diversos enfoques teóricos de los movimientos sociales, la teoría de Antonio Gramsci, y teniendo como referente la reforma de Córdoba estos autores y autora se preguntan ¿qué alcances y limitaciones presentó la acción colectiva del movimiento estudiantil en Villarreal durante los años 2013 al 2016? Como respuestas, Liendo, Caravedo y Ruiz afirman que la reforma universitaria de 2014 presenta las características de una revolución pasiva progresiva, en tanto adquiere algunos elementos reivindicativos de los sectores más radicalizados y subalternos que demandaron el voto universal para la elección de autoridades y mecanismos de regulación supra universitarios para luchar contra la corrupción y afianzar el rol subsidiario del estado en la educación, en un modelo neoliberal de veintiséis años ininterrumpidos. Además, concluyen que la movilización de los estudiantes da cuenta del surgimiento de una subjetividad política en Villarreal, relativamente al margen de las clases sociales y asociada con la manifestación de acciones democráticas denunciando y luchando contra la corrupción. Liendo, Caravedo y Ruiz recomiendan que, en el marco de la nueva ley universitaria y en el proceso de conquista paulatina de su autonomía, los estudiantes organizados tienen el desafío de redirigir sus esfuerzos hacia el gobierno universitario con el fin de quebrar la hegemonía de los intereses partidarios ocultos, visibilizados en tiempo de crisis, y constituir herramientas democráticas e institucionales de gestión universitaria para beneficio común. 


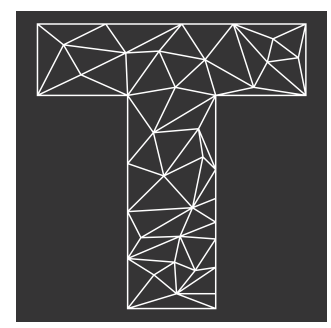

Wilmer Rodríguez-Vega y Mario Chacón-Rivas discuten la importancia de la participación de las personas usuarias con discapacidad visual en los procesos de evaluación de la accesibilidad digital o web desde el Observatorio de Tecnologías Accesibles e Inclusivas (OTAI) del Instituto Tecnológico de Costa Rica, en Cartago, Costa Rica, para el establecimiento de criterios que permitan enfrentar la discriminación y; por otro lado favorecer la accesibilidad universal que, en la estructura social, se ejerce hacia esta población. Dicha participación no solo puede contribuir a la creación de dispositivos, interfaces, sistemas operativos, herramientas de apoyo, documentos; sino que establece condiciones positivas para el ejercicio de los derechos humanos de las personas con discapacidad visual. En este sentido, el OTAI y otros proyectos de Inclutec es una instancia (living lab) de investigación e innovación interdisciplinaria, con equipos y sistemas socio-técnicos que propone metodologías, marcos heurísticos, test de usabilidad y criterios de evaluación de la accesibilidad, desde la fase de desarrollo de proyectos digitales, hasta la evaluación de la interfaz final.

Oscar Andrés Acuña Muñoz analiza la incidencia de distintos factores socioculturales y demográficos que inciden en la adopción y toma de decisiones de las personas al asumir un servicio financiero. A partir de la teoría de acción planificada y la teoría de la difusión de las innovaciones y un abordaje estadístico, según Acuña, permitieron conocer que la percepción de utilidad y el 


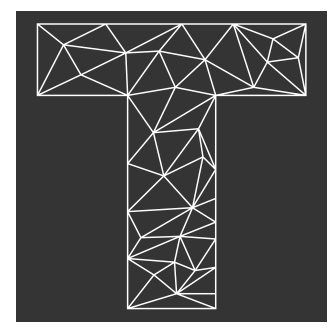

conocimiento son factores cruciales para la toma de decisión de asumir el riesgo de un servicio financiero. No obstante, distintas crisis, económicas y sanitarias como la generada por el COVID-19, nacionales e internacionales pueden contribuir al incremento de la cautela al asumir un servicio financiero.

Maritza Marín-Herrera, Vernon Soto Lugo, Silvia Solano Ulate e Ivannia Barboza Leitón analizan, desde la ecología política latinoamericana y caribeña, distintas prácticas culturales ancestrales del pueblo indígena boruca y principalmente aquellas asociadas con la recolección de sal y el teñido de tela con el Plicopurpura pansa (conocido como múrice), en las costas del pacífico sur de Costa Rica. En este contexto, este grupo de investigadoras e investigadores elabora una revisión bibliográfica en la que analiza las condiciones sociales de esta comunidad, así como la relación contradictoria entre distintas políticas, convenios nacionales e internacionales y un modelo de desarrollo extractivista que asedia a la naturaleza y la conservación de dichas prácticas culturales en zonas costeras. Al respecto, el trabajo destaca tres ejes vinculados a la práctica cultural de la extracción de sal por parte de pueblos indígenas: como producto de consumo humano que fue y es extraído de manera artesanal por las comunidades indígenas costeras y no costeras así como para el intercambio con otros pueblos; la transformación de la práctica extractiva de la sal en una industrial durante la Colonia que generó explotación laboral indígena e invasión territorial de estos pueblos y; se revela un vacío bibliográfico acerca de la importancia cultural de la sal para el caso costarricense. No obstante, este trabajo aporta 


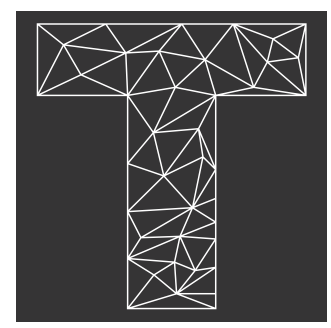

elementos novedosos sobre la extracción, selección y empleo de la sal y el teñido con el múrice o Plicopurpura pansa como tareas ejecutadas principalmente por mujeres indígenas borucas; la necesidad urgente de la conservación y cuidad de ese molusco en las playas Chamán y Ventanas y; aporta conocimiento para los procesos de lucha socio-política y ecológica, situada.

Cristina Estrada Porras explora desde la disciplina de la ingeniería forestal, distintos aportes brindados por la bioeconomía y el uso de Sistemas de Información Geográfica (SIG) como alternativas políticas, éticas y ecológicas para resolver problemática medioambiental generada por el capitalismo. Así, este trabajo revisa distintas fuentes bibliográficas para argumentar que la bioeconomía es un sistema económico basado en la aplicación de conocimientos y tecnologías para la producción de bienes y servicios a partir del aprovechamiento sostenible de los recursos biológicos naturales. Asimismo, a partir de la revisión de tres casos concretos, este trabajo plantea que los SIG contribuyen a la construcción de alternativas a problemáticas ambientales en campos como el análisis de la pérdida de suelos de la subcuenca del río Tempisquito en Guanacaste, Costa Rica; el estudiado de la producción de agua de una cuenca hidrológica en la subcuenca del Sector Prusia del Parque Nacional Volcán Irazú en Cartago, Costa Rica y; el análisis de la respuesta hidrológica del suelo de una cuenca modelada en laboratorio con diferentes tratamientos de sustratos. 


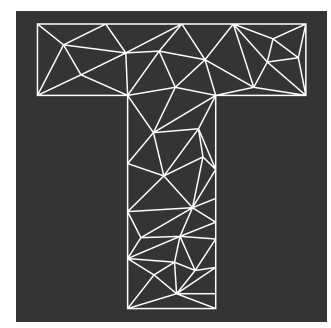

Agradezco a las y los autores, evaluadores, estudiantes asistentes, al Consejo Científico-Editorial y a todas aquellas personas que han contribuido a esta publicación de Trama.

La producción fotográfica de este número de Trama la realicé un 12 de setiembre 2017 participando en una marcha en defensa de la universidad pública en San José, Costa Rica frente a los ataques de grupos de presión alienados con políticas neoliberales orientadas a la venta de activos públicos y su privatización, recorte presupuestario al estado social, socavamiento de la institucionalidad pública y de derecho, entre otras. No obstante, esta marcha estudiantil puso en evidencia la permanente lucha por causas justas como los derechos humanos y de la naturaleza, la democracia y la soberanía de los pueblos.

Este editorial de Trama lo escribo demandando justicia para María Tacsan, amiga, quien fuera asesinada por su pareja en San Rafael de Heredia, Costa Rica en 2020; y dedico este número de Trama en conmemoración de todas aquellas mujeres a quienes se les arrebató la vida, y en no pocos casos, impunemente. 


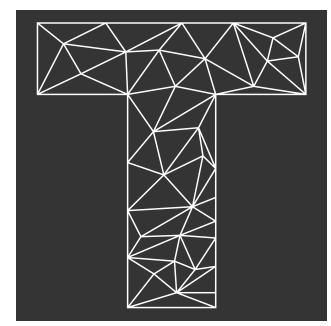

DOI: 10.18845/tramarcsh.v9i2.5566

Francisco Javier Mojica-Mendieta, Dr. Director-Editor de Trama, Revista de Ciencias Sociales y Humanidades.

Profesor - Investigador de la Escuela de Ciencias Sociales. Instituto Tecnológico de Costa Rica.

Correo electrónico: fmojica@itcr.ac.cr ORCID: https://orcid.org/0000-0003-3462-5394

Cartago, Costa Rica. 17 de Diciembre de 2020 